\title{
Preparation of Hemin-Immobilized Layer-by-Layer Films on the Surface of Glassy Carbon Electrodes as Hydrogen Peroxide Sensors
}

\author{
Baozhen Wang, Jun-ichi Anzai*, Weilei Gong¹, \\ Maoqing Wang ${ }^{1}$ and Xiaoyan Du${ }^{1, *}$ \\ Graduate School of Pharmaceutical Sciences, Tohoku University, \\ Aramaki, Aoba-ku, Sendai 980-8578, Japan \\ ${ }^{1}$ Public Health College, Harbin Medical University, Harbin 150081, P. R. China
}

(Received March 17, 2008; accepted July 14, 2008)

Key words: LbL film, hemin, hydrogen peroxide, sensor

Hemin-confined thin films composed of poly(ethyleneimine) (PEI) and carboxymethylcellulose (CMC) were fabricated by layer-by-layer (LbL) deposition on the surface of a glassy carbon (GC) electrode for the detection of hydrogen peroxide $\left(\mathrm{H}_{2} \mathrm{O}_{2}\right)$. Hemin could be easily immobilized in LbL films by immersing an LbL-filmmodified electrode in hemin solution, irrespective of the electric charge on the surface layer of the film. The results showed that a small amount of hemin located near the surface of the electrode is involved in the electrochemical reaction, while most of the hemin molecules in the film are not involved. The hemin-modified electrode showed an excellent amperometric response to $\mathrm{H}_{2} \mathrm{O}_{2}$ on the basis of electrocatalytic reduction under electrode potentials of -0.6 and $-0.4 \mathrm{~V}$. The hemin-modified electrode exhibited a linear calibration graph for $0.005-0.8 \mathrm{mM} \mathrm{H}_{2} \mathrm{O}_{2}$ when operated at $-0.6 \mathrm{~V}$. The hemin-modified electrode was found to be stable for about 2 weeks. Thus, the usefulness of LbL films composed of PEI and CMC as a scaffold for immobilizing hemin was demonstrated.

\section{Introduction}

Hydrogen peroxide $\left(\mathrm{H}_{2} \mathrm{O}_{2}\right)$ is widely used in many fields such as the pharmaceutical, chemical, iron and steel, textile and food industries as sterilizing, oxidizing, deodorizing or bleaching agent. Industrial waste products contaminated with $\mathrm{H}_{2} \mathrm{O}_{2}$ are known to be harmful to human beings as well as to the environment. Therefore, the detection of $\mathrm{H}_{2} \mathrm{O}_{2}$ is of crucial importance in industry and environmental science. ${ }^{(1)}$ Many methods including titration, spectrophotometry, fluorescence, chemiluminescence and electrochemistry have been used to detect $\mathrm{H}_{2} \mathrm{O}_{2}$ in laboratories. ${ }^{(2)}$ Electrochemical sensors based on peroxidase have attracted much attention because of their simplicity,

${ }^{*}$ Corresponding author: e-mail: junanzai@mail.pharm.tohoku.ac.jp, duxiaoyanha@163.com 
high sensitivity and rapidity. ${ }^{(3,4)}$ Horseradish peroxidase (HRP) is a widely used enzyme for this purpose. ${ }^{(5-12)}$

It is known that many types of protein can catalyze the redox reaction of $\mathrm{H}_{2} \mathrm{O}_{2}$ in addition to peroxidases. In fact, heme proteins such as cytochrome $\mathrm{C}$ (Cyt $\mathrm{C}){ }^{(13)}$ hemoglobin $(\mathrm{Hb})^{(14-16)}$ and myoglobin $(\mathrm{Mb})^{(17-19)}$ have also been used extensively for fabricating $\mathrm{H}_{2} \mathrm{O}_{2}$ sensors because of their peroxidase-like catalytic activity to $\mathrm{H}_{2} \mathrm{O}_{2}$. ${ }^{(20-22)}$ It has been found that hemin, a prosthetic group of $\mathrm{Mb}$ or $\mathrm{Hb}$, and microperoxidase-11 and microperoxidase- 8 also exhibit peroxidase activity even after they are immobilized on an electrode surface. ${ }^{(23-27)}$ In this study, we prepared electrochemical $\mathrm{H}_{2} \mathrm{O}_{2}$ sensors using hemin as a catalyst.

Hemin (iron protoporphyrin IX) is found in the active center of heme proteins and has been immobilized on the surface of electrodes to develop electrochemical sensors for organohalides, dioxygen, tryptophan and $\mathrm{H}_{2} \mathrm{O}_{2} \cdot{ }^{(28-32)}$ In these heminimmobilized electrodes, however, the immobilization of hemin on the electrode involves a somewhat complicated and time-consuming procedure including polymer synthesis, electropolymerization and carbon nanotube processing.

In this study, to develop a simple protocol for immobilizing hemin on the surface of electrodes, glassy carbon (GC) electrodes coated with a layer-by-layer (LbL) thin film composed of poly(ethyleneimine) (PEI) and carboxymethylcellulose (CMC) are used. The LbL thin film is a widely used technique for the fabrication of functional materials and biosensors because of its simplicity and versatility. ${ }^{(33-38)}$ In this context, we have reported a preliminary result for the $\mathrm{H}_{2} \mathrm{O}_{2}$ sensor prepared using hemin-modified LbL films. ${ }^{(39)}$ We report in detail the preparation of a $\mathrm{H}_{2} \mathrm{O}_{2}$ sensor comprising GC electrodes coated with hemin-immobilized LbL films. The $\mathrm{H}_{2} \mathrm{O}_{2}$ sensor would be useful for detecting $\mathrm{H}_{2} \mathrm{O}_{2}$ in industries and also for developing biosensors by coupling with enzymes that generate $\mathrm{H}_{2} \mathrm{O}_{2}$ as a reaction product.

\section{Materials and Methods}

\subsection{Reagents}

Iron(III) protoporphyrin IX chloride (hemin) was purchased from Tokyo Kasei Co. (Tokyo, Japan) and used as received. An aqueous solution of poly(ethyleneimine) (PEI; MW, 60,000-80,000) (30\%) was purchased from Nacalai Tesque Co. (Kyoto, Japan). PEI has a random branched structure, the ratio of primary, secondary and tertiary amino groups being nominally about 1:2:1. Sodium carboxymethylcellulose (CMC; MW, $260,000)$ and $p$-aminobenzenesulfonic acid ( $p$-ABS) were purchased from Tokyo Kasei Co. The chemical structure of hemin is shown in Fig. 1. All other reagents used were of the highest grade available and used without further purification. A $10 \mathrm{mM}$ Tris- $\mathrm{HCl}$ buffer containing $50 \mathrm{mM} \mathrm{NaCl}(\mathrm{pH}$ 7.4) was used throughout unless otherwise noted. All solutions were prepared in high-purity water (Milli-Q, Millipore) immediately before use.

\subsection{Apparatus and measurements}

All measurements were performed on an electrochemical analyzer (ALS, model 660B) using a conventional three-electrode system consisting of the hemin-modified GC 


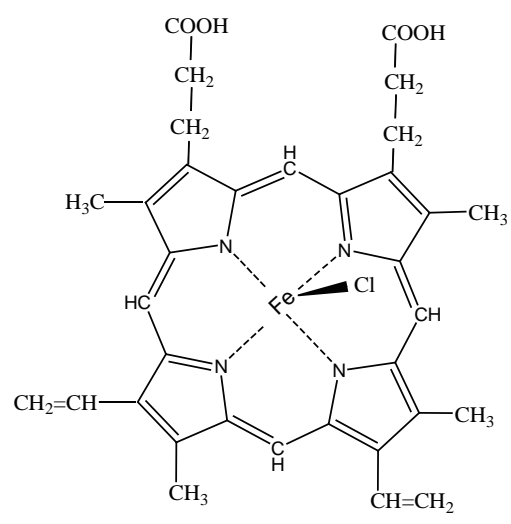

Fig. 1. Chemical structure of hemin.

electrode as a working electrode, a $\mathrm{Ag} / \mathrm{AgCl}$ reference electrode and a platinum wire as a counter electrode. All electrochemical measurements were carried out under a $\mathrm{N}_{2}$ atmosphere after deoxygenation for $15 \mathrm{~min}$ because the measurement was significantly disturbed by dissolved oxygen. The temperature of the sample solutions was maintained at room temperature (ca. $20^{\circ} \mathrm{C}$ ) during the measurements. The hemin-modified electrodes were stored in $10 \mathrm{mM}$ Tris- $\mathrm{HCl}$ buffer $(\mathrm{pH} 7.4)$ at $4^{\circ} \mathrm{C}$ when not in use.

UV-visible absorption measurements were carried out on a UV-3100PC spectrometer (Shimadzu Co., Kyoto, Japan) at room temperature after the quartz slide modified with multilayer films was dipped in hemin solution for $60 \mathrm{~min}$ and then rinsed in the working buffer overnight.

\subsection{Preparation of hemin-immobilized electrode}

The surface of a GC electrode (diameter, $3 \mathrm{~mm}$ ) was polished thoroughly using an alumina suspension and rinsed in water under sonication for $10 \mathrm{~min}$. Then the polished electrode was electrochemically modified with $p$-ABS by scanning the electrode potential over the range of $+0.5-+1.4 \mathrm{~V}$ at a scan rate of $0.01 \mathrm{Vs}^{-1}$ in $5 \mathrm{mM}$-ABS aqueous solution containing $0.1 \mathrm{M} \mathrm{KCl}$ in accordance with the literature. ${ }^{(40)}$ The $p$-ABSmodified GC electrode was then coated with LbL multilayer films by alternate and repeated depositions of PEI and CMC in $0.5 \mathrm{mg} / \mathrm{mL}$ solutions as previously reported. ${ }^{(41)}$ Briefly, the $p$-ABS-modified GC electrode, whose surface is negatively charged, was first immersed in $0.5 \mathrm{mg} \mathrm{mL}^{-1}$ PEI solution for $30 \mathrm{~min}$ to deposit the first layer on the p-ABS-modified electrode and rinsed in the working buffer for $10 \mathrm{~min}$. The PEI-treated electrode was then immersed in $0.5 \mathrm{mg} \mathrm{mL}^{-1} \mathrm{CMC}$ solution for $30 \mathrm{~min}$ and rinsed similarly. By this treatment, a polyamine-polysaccharide bilayer film can be prepared on the surface of the electrode. Multilayer films with the desired number of layers were prepared by repeating the deposition. The LbL-film-modified electrode thus prepared was immersed in $0.05 \mathrm{mM}$ hemin solution for $60 \mathrm{~min}$ to immobilize hemin in the LbL film. The hemin solution was prepared by diluting a stock solution of hemin in $0.1 \mathrm{~N}$ $\mathrm{KOH}$. 


\section{Results and Discussion}

\subsection{UV-visible absorption spectra of hemin immobilized in PEI/CMC multilayer films}

Figure 2 displays the UV-visible absorption spectra of hemin immobilized in (PEI$\mathrm{CMC})_{n}$ multilayer films $(n=1-5)$ recorded in a $10 \mathrm{mM}$ Tris-HCl buffer containing $50 \mathrm{mM}$ $\mathrm{NaCl}$. The absorption intensity of hemin increased with increasing number of layers. All the spectra displayed an absorption maximum at approximately $395 \mathrm{~nm}$ called the Soret band with a shoulder at approximately $359 \mathrm{~nm}$. It is known that the aggregation of hemin is associated with the lowering of absorbance and the broadening of the Soret band, while the monomer gives rise to a sharp intense Soret band with a maximum at approximately $395 \mathrm{~nm}$ in neutral and basic solutions. ${ }^{(42,43)}$ Therefore, the hemin immobilized in the LbL film is predominantly in monomeric form. A small amount of dimer might be responsible for the shoulder absorption. Similar spectral features are observed for the PEI-terminated (PEI-CMC) ${ }_{n}$ PEI films.

\subsection{Preparation of hemin-immobilized LbL film-modified electrodes}

We have reported previously that $\mathrm{PEI} / \mathrm{CMC}$ multilayer films are permeable to small ions and molecules irrespective of the thickness and the sign of the surface charge of the films. ${ }^{(41)}$ Figure 3 displays cyclic voltammograms (CVs) associated with the redox reactions of hemin on the GC electrode coated with the (PEI-CMC) $)_{5}$ multilayer film. The CVs were recorded occasionally over $90 \mathrm{~min}$, during which the (PEI-CMC) $)_{5}$ film coated electrode was immersed in $0.05 \mathrm{mM}$ hemin solution ( $\mathrm{pH}$ 7.4). No redox peak was observed immediately after the electrode was dipped into the hemin solution (0 min). This is because no hemin molecules reach the electrode surface due to the slow diffusion of hemin in the film. The redox current of hemin increased with increasing time, and a pair of well-defined redox peaks were clearly observed after 60 min. Similar results were observed for the PEI-terminated (PEI-CMC) 5 PEI film modified electrode (data not shown). These results suggest that hemin permeates the LbL films irrespective of the sign of the electric charge on the surface of the film. On the basis of the results reported

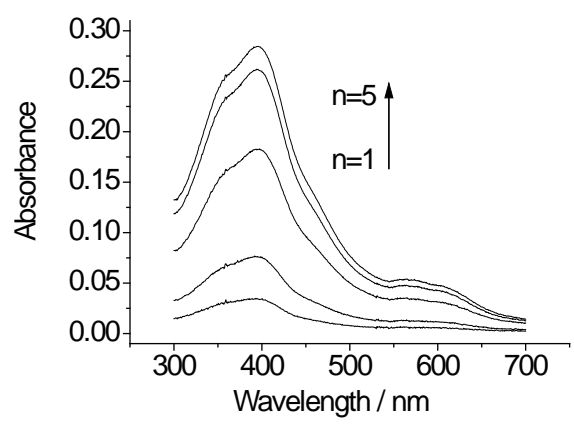

Fig. 2. UV-visible absorption spectra of hemin immobilized in (PEI-CMC) $)_{n}$ multilayer films $(n=$ 1-5). Hemin was immobilized in the films by immersing the films in $0.05 \mathrm{mM}$ hemin solution in $10 \mathrm{mM}$ Tris-HCl buffer containing $50 \mathrm{mM} \mathrm{NaCl}$ (pH 7.4) for $1 \mathrm{~h}$. 


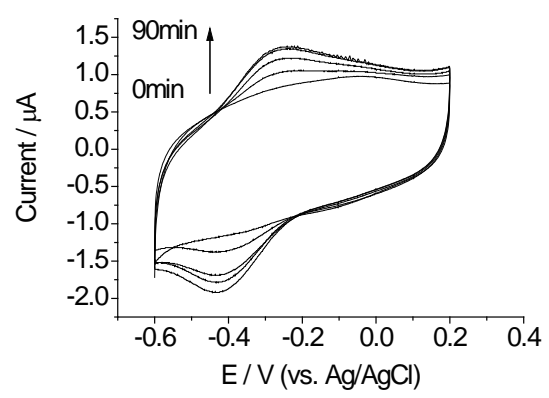

Fig. 3. Cyclic voltammograms (CVs) of hemin on the GC electrode coated with (PEI-CMC) 5 multilayer film as a function of dipping time. Scan rate: $0.05 \mathrm{~V} \mathrm{~s}^{-1}$. The dipping times in $0.05 \mathrm{mM}$ hemin solution were $0,15,30,60$ and $90 \mathrm{~min}$.

in Fig. 3, we treated the LbL-film-modified electrodes in $0.05 \mathrm{mM}$ hemin solution for $60 \mathrm{~min}$ to immobilize hemin in the film throughout this study. The difference between the oxidation and reduction potentials in the CVs is ca. $150 \mathrm{mV}$, suggesting a quasi-reversible one-electron transfer involving an $\mathrm{Fe}(\mathrm{III}) / \mathrm{Fe}(\mathrm{II})$ redox couple in the immobilized hemin. ${ }^{(44)}$

Figure 4 shows a comparison of the total amount of hemin immobilized in the multilayer films and that involved in the electrochemical reaction. The amount of hemin confined in the (PEI-CMC) ${ }_{n}$ and (PEI-CMC) ${ }_{n} \mathrm{PEI}$ films increased with increasing number of layers. It is interesting that the amount of hemin involved in the redox reaction is rather low for all the films as compared with the total amount of hemin immobilized. For example, the amounts of hemin involved in the redox reaction are $3.9 \times 10^{-10}$ and $2.6 \times 10^{-10} \mathrm{~mol} \mathrm{~cm}^{-2}$ for the (PEI-CMC) $)_{5}$ and (PEI-CMC) $)_{5}$ PEI films, while the amounts of hemin immobilized in the (PEI-CMC) $)_{5}$ and (PEI-CMC) $)_{5}$ PEI films were $4.3 \times 10^{-9}$ and $0.5 \times 10^{-8} \mathrm{~mol} \mathrm{~cm}^{-2}$, respectively. Thus, the percentages of hemin involved in the redox reaction in the (PEI-CMC) $)_{5}$ and (PEI-CMC) $)_{5} \mathrm{PEI}$ films were about 9.0 and $4.9 \%$, respectively. Therefore, it is likely that only the hemin located near the electrode surface is involved in the redox reaction, while most of the hemin molecules immobilized in the outer layers in the LbL film cannot be involved in the redox process.

Table 1 shows the effect of ionic strength on the amount of hemin immobilized in the film. There is little difference between the two types of films in the loading of hemin when it is immobilized under a lower ionic strength $(10,50$, and $150 \mathrm{mM} \mathrm{NaCl})$. Under a higher ionic strength, however, the amount of hemin in the (PEI-CMC) $)_{5}$ film is significantly higher than that in the (PEI-CMC) ${ }_{5} \mathrm{PEI}$ film. This may originate from the fact that the high ionic strength affects the permeability of the multilayer films. ${ }^{(45-47)}$

Figure 5 shows the relationship between the concentration of hemin in the dipping solution and the amounts of hemin immobilized in the (PEI-CMC) $)_{5}$ and (PEI-CMC) $)_{5} \mathrm{PEI}$ films. The total amount of hemin immobilized in the multilayer films slightly increases when the hemin concentration is $0.1 \mathrm{mM}$ as compared with that in $0.05 \mathrm{mM}$ hemin solution. However, in the hemin solutions above $0.1 \mathrm{mM}$, the amounts of hemin immobilized in the film are nearly the same with each other. 


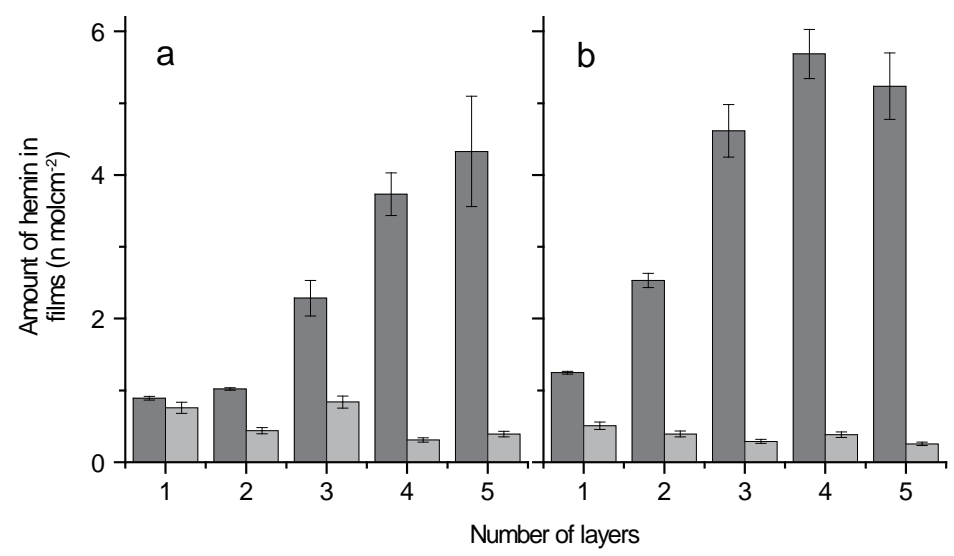

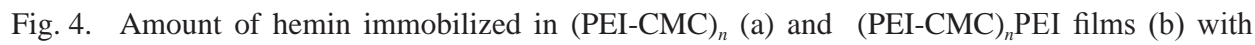
different numbers of layers. The gray bars (left) and light-gray bars (right) show the data obtained from UV-visible absorption spectra and CV, respectively. The data are based on three independent preparations.

Table 1

Loading of hemin in the LbL films as a function of the ionic strength of hemin solution.

\begin{tabular}{ccc}
\hline Concentration of $\mathrm{NaCl} / \mathrm{mM}$ & \multicolumn{2}{c}{ Loading of hemin in the film $/ 10^{-9} \mathrm{~mol} \mathrm{~cm}^{-2}$} \\
\cline { 2 - 3 } & (PEI-CMC) $)_{5}$ film & (PEI-CMC) $)_{5}$ PEI film \\
\hline 10 & $3.8 \pm 0.8$ & $4.5 \pm 0.6$ \\
50 & $4.4 \pm 0.8$ & $5.2 \pm 0.5$ \\
150 & $5.5 \pm 0.1$ & $5.5 \pm 0.6$ \\
300 & $4.8 \pm 0.6$ & $1.8 \pm 0.3$ \\
\hline
\end{tabular}

The listed data are calculated based on 4 independent preparations.

\subsection{Catalytic reduction of $\mathrm{H}_{2} \mathrm{O}_{2}$ on the hemin-immobilized electrode}

Figure 6 shows the $\mathrm{CVs}$ of $\mathrm{H}_{2} \mathrm{O}_{2}$ on the hemin-immobilized (PEI-CMC) $)_{5}$-film-modified electrode. The cathodic current of the $\mathrm{CVs}$ increased with increasing concentration of $\mathrm{H}_{2} \mathrm{O}_{2}$, showing that the hemin-modified electrode catalyzes the reduction of $\mathrm{H}_{2} \mathrm{O}_{2}$.

For the amperometric measurement of $\mathrm{H}_{2} \mathrm{O}_{2}$, the electrode potential was fixed at $0.2,0,-0.2,-0.4$ or $-0.6 \mathrm{~V}$. Figure 7 shows the amperometric response of the heminimmobilized (PEI-CMC) $)_{5}$-film-modified electrode to $\mathrm{H}_{2} \mathrm{O}_{2}$. Curves $\mathrm{c}$ and $\mathrm{b}$ are the responses under electrode potentials of -0.6 and $-0.4 \mathrm{~V}$, respectively. The response to $0.1 \mathrm{mM} \mathrm{H}_{2} \mathrm{O}_{2}$ is indicated by the arrow in the figure. In contrast, the response was negligible on the hemin-free (PEI-CMC) $)_{5}$-film-modified electrode $\left(0.1 \mathrm{mM} \mathrm{H}_{2} \mathrm{O}_{2}\right.$ was added dropwise up to a final concentration of $1 \mathrm{mM}$ ). The hemin-immobilized electrode showed a response to $\mathrm{H}_{2} \mathrm{O}_{2}$ even under a positive potential at $0.2 \mathrm{~V}$ (see inset). This is probably due to the formation of an intermediate $\mathrm{Fe}(\mathrm{III})-\mathrm{H}_{2} \mathrm{O}_{2}$ complex that is decomposed to an $\mathrm{Fe}(\mathrm{IV})$-oxo species, which is known to be reduced under a positive potential. ${ }^{(48,49)}$ There was no response on the hemin-free electrode under the same positive potential. The response of the hemin-confined electrode is rapid, the response time being about 5-15 s. 


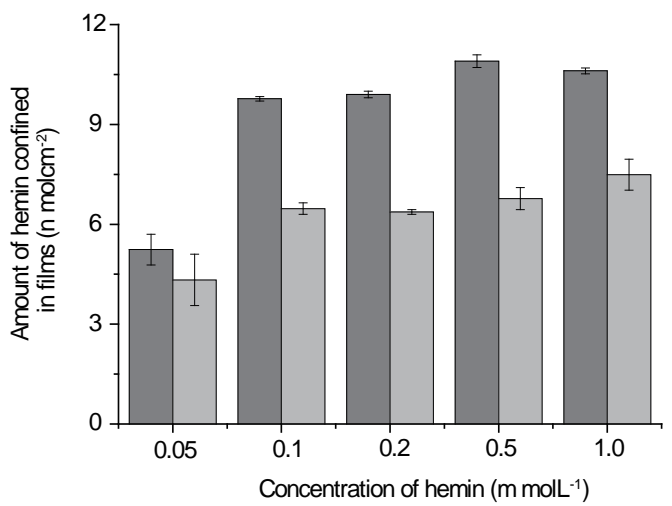

Fig. 5. Effect of the concentration of hemin on the amount of hemin immobilized in the (PEI-CMC) (light-gray bars, right) and (PEI-CMC) $)_{5} \mathrm{PEI}$ (gray bars, left) films. The data are based on three independent preparations.

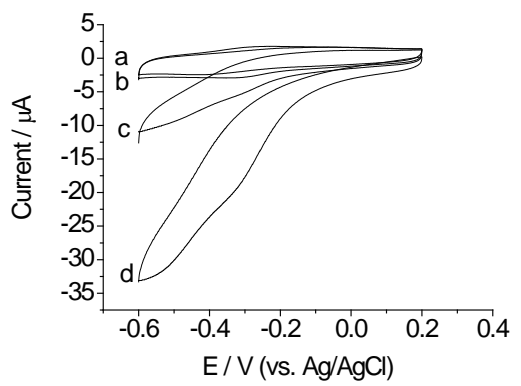

Fig. 6. CVs of hemin-modified (PEI-CMC) $)_{5}$-film-coated GC electrode in the absence (a) and presence of 0.05 (b), 0.5 (c) and $1.0 \mathrm{mM} \mathrm{H}_{2} \mathrm{O}_{2}$ (d) in $10 \mathrm{mM}$ Tris-HCl buffer (pH 7.4) containing $50 \mathrm{mM} \mathrm{NaCl}$. Scan rate: $0.05 \mathrm{Vs}^{-1}$.

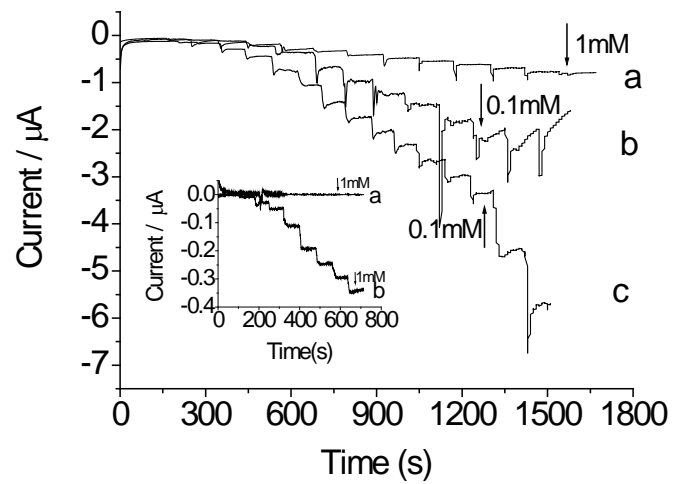

Fig. 7. Amperometric responses of hemin-free (a) and hemin-modified (PEI-CMC) $)_{5}$-film-coated GC electrodes (b and c) to $\mathrm{H}_{2} \mathrm{O}_{2}$ in $10 \mathrm{mM}$ Tris-HCl buffer ( $\mathrm{pH}$ 7.4) containing $50 \mathrm{mM} \mathrm{NaCl}$. The electrode potential was set at -0.4 for $b$ and $-0.6 \mathrm{~V}$ for a and c. The concentration of $\mathrm{H}_{2} \mathrm{O}_{2}$ in the sample solution was increased stepwise and the final concentrations are $1,0.2$, and $0.2 \mathrm{mM}$ for a, b and c, respectively. Inset: Reactions of $\mathrm{H}_{2} \mathrm{O}_{2}$ on hemin-free (a) and hemin-confined (PEI$\mathrm{CMC})_{5}$ PEI-modified electrodes (b) at an applied potential of $0.2 \mathrm{~V}$. The final concentration of $\mathrm{H}_{2} \mathrm{O}_{2}$ was $1 \mathrm{mM}$. 
Figure 8 shows calibration curves for $\mathrm{H}_{2} \mathrm{O}_{2}$ over the concentration range of $0.005-1 \mathrm{mM}$ for the hemin-immobilized (PEI-CMC) $5_{5}^{-}$and (PEI-CMC) ${ }_{5} \mathrm{PEI}$-film-coated electrodes measured at $-0.6 \mathrm{~V}$. A linear relationship is obtained in the range of $0.005-0.8 \mathrm{mM} \mathrm{H}_{2} \mathrm{O}_{2}$. The detection limit is $0.1 \mu \mathrm{M}$ when the signal-to-noise ratio is 3 , and the regression equations are $y=-19.1 X-0.5$ and $y=-22.7 X-0.4\left(\mathrm{mM}\right.$ of $\left.\mathrm{H}_{2} \mathrm{O}_{2}\right)$ for the (PEI-CMC) $)_{5}$ and (PEI-CMC) $)_{5}$ PEI multilayer films, respectively.

\subsection{Stability of the hemin-immobilized electrode}

To evaluate the stability of the hemin-modified electrode, the response of the electrode to 0.001-0.5 $\mathrm{mM} \mathrm{H}_{2} \mathrm{O}_{2}$ was measured every day for 3 weeks (Fig. 9). The response was relatively stable during the first 2 weeks for both films. After 2 weeks,

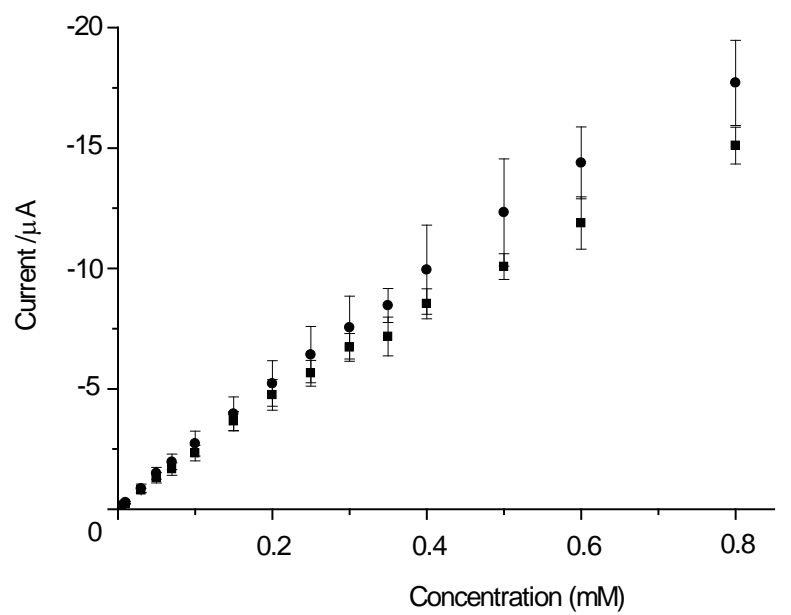

Fig. 8. Typical calibration graphs for hemin-modified (PEI-CMC) $)_{5}$-film- (ø) and (PEICMC) 5 PEI-film- $\left(\bullet\right.$ ) coated GC electrodes to $\mathrm{H}_{2} \mathrm{O}_{2}$ in $10 \mathrm{mM}$ Tris-HCl buffer (pH 7.4) containing $50 \mathrm{mM} \mathrm{NaCl}$. The applied potential was set at $-0.6 \mathrm{~V}$. The data are based on three independent measurements.

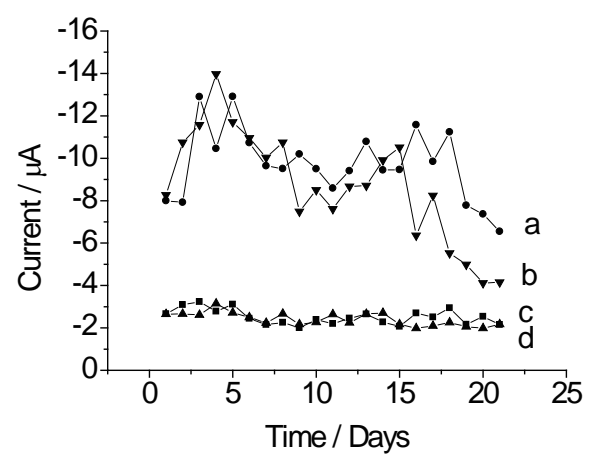

Fig. 9. Stability of hemin-confined (PEI-CMC) $)_{5}$-film (b and d) and (PEI-CMC) $)_{5}$ PEI-film-coated electrodes (a and c). The concentrations of $\mathrm{H}_{2} \mathrm{O}_{2}$ were $0.5 \mathrm{mM}$ for a and $\mathrm{b}$ and $0.1 \mathrm{mM}$ for $\mathrm{c}$ and $\mathrm{d}$. The applied potential was set at $-0.6 \mathrm{~V}$. 
however, the response began to decrease day by day. This is probably due to the leakage of hemin from the LbL film.

\section{Conclusions}

We successfully prepared a hemin-modified electrode as a $\mathrm{H}_{2} \mathrm{O}_{2}$ sensor using LbL films composed of PEI and CMC. Hemin can permeate the LbL films irrespective of the sign of the electric charge of the surface to be immobilized in the film. The amount of hemin confined in the LbL films depended on the number of layers. Hemin immobilized in the LbL films exhibited an electrocatalytic activity to $\mathrm{H}_{2} \mathrm{O}_{2}$ under applied potentials of -0.4 and $-0.6 \mathrm{~V}$. Thus, the usefulness of an $\mathrm{LbL}$ film as a scaffold for immobilizing hemin was established. The LbL-film-based $\mathrm{H}_{2} \mathrm{O}_{2}$ sensors may be useful for detecting $\mathrm{H}_{2} \mathrm{O}_{2}$ because of their easy preparation and high sensitivity. Further improvement in the stability of the hemin-immobilized films is possible by the covalent attachment of hemin to the film through a coupling agent or by using hemin-modified polymers to construct LbL films.

\section{Acknowledgment}

The present work was supported in part by a grant from Heiwa Nakajima Foundation.

\section{References}

1 U. Sansal and G. Somer: Food Chem. 65 (1999) 259.

2 A. J. Guwy, F. R. Hawkes, S. R. Martin, D. L. Hawkes and P. Cunnah: Wat. Res. 34 (2000) 2191.

3 S. Uchiyama and Y. Sano: Electroanalysis 12 (2000) 817.

4 A. Lindgren, T. Ruzgas, L. Gorton, E. Csöregi, G. B. Ardila, I. Y. Sakharov and I. G. Gazaryan: Biosens. Bioelectron. 15 (2000) 491.

5 T. Ruzgas, E. Csöregi, J. Emnéus, L. Gorton and G. Marko-Varga: Anal. Chim. Acta 330 (1996) 123.

6 S. S. Rzaola, E. Aktas, J. C. Viré and J. M. Kauffmann: Analyst 125 (2000) 79.

7 X. Xu, S. Liu and H. Ju: Sensors 3 (2003) 350.

8 Y. Xu, W. Peng, X. Liu and G. Li: Biosens. Bioelectron. 20 (2004) 533.

9 T. Tangkuaram, C. Ponchio, T. Kangkasomboon, P. Katikawong and W. Veerasai: Biosens. Bioelectron. 22 (2007) 2071.

10 C. Lei and J. Deng: Anal. Chem. 68 (1996) 3344.

11 I. S. Alpeeva, M. N. Nistor, J. C. Leon, E. Csöregi and I. Y. Sakharov: Biosens. Bioelectron. 21 (2005) 742.

12 F. Gao, R. Yuan, Y. Chai, S. Chen, S. Cao and M. Tang: J. Biochem. Biophys. Methods 70 (2007) 407.

13 J. Feng, G. Zhao, J. Xu and H. Chen: Anal. Biochem. 342 (2005) 280.

14 W. Sun, H. Jiang and K. Jiao: J. Chem. Sci. 117 (2005) 317.

15 S. Chen and C. Tseng: J. Electroanal. Chem. 575 (2005) 147.

16 X. Liu, T. Chen, L. Liu and G. Li: Sens. Actuators B 113 (2006) 106.

17 W. Yang, Y. Li, Y. Bai and C. Sun: Sens. Actuators B 115 (2006) 42. 
18 H. Lu and N. Hu: J. Phys. Chem. B 111 (2007) 1984.

19 G. Wang, H. Lu and N. Hu: J. Electroanal. Chem. 599 (2007) 91.

20 L. Gorton, A. Lindgren, T. Larsson, F. D. Munteanu, T. Ruzgas and I. G. Gazaryan: Anal. Chim. Acta 400 (1999) 91.

21 S. Ozaki, M. P. Roach, T. Matsui and Y. Watanabe: Acc. Chem. Res. 34 (2001) 818.

22 H. Liu, Z. Tian, Z. Lu, Z. Zhang, M. Zhang and D. Pang: Biosens. Bioelectron. 20 (2004) 294.

23 T. Ruzgas, A. Gaigalas and L. Gorton: J. Electroanal. Chem. 469 (1999) 123.

24 A. Spector, W. Zhou, W. Ma, C. F. Chignell and K. J. Reszka: Exp. Eye Res. 71 (2000) 183.

25 M. Wang, F. Zhao, Y. Liu and S. Dong: Biosens. Bioelectron. 21 (2005) 159.

26 D. A. Baldwin, H. M. Marques and J. M. Pratt: FEBS Lett. 183 (1985) 309.

27 T. Lötzbeyer, W. Schuhmann and H. Schmidt: J. Electroanal. Chem. 395 (1995) 341.

28 N. Nakashima, T. Tokunaga, H. Owaki, H. Murakami and T. Sagara: Coll. Surf. A 169 (2000) 163.

29 A. G. Rosa, E. Castro-Quezada, S. Gutiérrez-Granados, F. Bedioui and A. Alatorre-Ordaz: Electrochem. Commun. 7 (2005) 853.

30 N. Zheng, Y. Zeng, P. G. Osborne, Y. Li, W. Chang and Z. Wang: J. Appl. Electrochem. 32 (2002) 129.

31 G. L. Turdean, I. C. Popescu, A. Curulli and G. Palleschi: Electrochim. Acta 51 (2006) 6435.

32 G. Chen, Z. Zhao, X. Wang, J. Duan and H. Chen: Anal. Chim. Acta 452 (2002) 245.

33 G. Decher: Science 277 (1997) 1232.

34 T. Hoshi, H. Saiki, S. Kuwazawa, C. Tsuchiya, Q. Chen and J. Anzai: Anal. Chem. 73 (2001) 5310.

35 J. Anzai and Y. Kobayashi: Langmuir 16 (2000) 2851.

36 S. S. Shiratori and M. F. Rubner: Macromolecules 33 (2000) 4213.

37 K. Sato, Y. Imoto, J. Sugama, S. Seki, H. Inoue, T. Odagiri, T. Hoshi and J. Anzai: Langmuir 21 (2005) 797.

38 H. Inoue, K. Sato and J. Anzai: Biomacromolecules 6 (2005) 27.

39 B. Wang, X. Du, M. Wang, W. Gong and J. Anzai: Electroanalysis 20 (2008) 1028.

40 X. Li, Y. Wan and C. Sun: J. Electroanal. Chem. 569 (2004) 79.

41 B. Wang and J. Anzai: Langmuir 23 (2007) 7378.

42 S. B. Brown and M. Shillcock: Biochem. J. 153 (1976) 279.

43 E. Tipping, B. Ketterer and P. Koskelo: Biochem. J. 169 (1978) 509.

44 R. W. Murray: Electroanalytical Chemistry, ed. A. I. Bard (Marcel Dekker, New York, (1983) p. 191.

45 S. L. Clark, M. F. Montague and P. T. Hammond: Macromolecules 30 (1997) 7237.

46 S. T. Dubas and J. B. Schlenoff: Macromolecules 32 (1999) 8153.

47 S. T. Dubas and J. B. Schlenoff: Macromolecules 34 (2001) 3736.

48 M. F. Perutz, M. Paoil and A. M. Lesk: Chem. Biol. 6 (1999) R291.

49 T. Tatsuma and T. Watanabe: Anal. Chem. 63 (1991) 1580. 